\title{
A pesquisa quantitativa em Psicologia da religião no Brasil
}

\author{
Quantitative research in Psychology of religion in Brazil
}

\section{Mary Rute Gomes Esperandio, Hartmut August*}

Pontifícia Universidade Católica do Paraná (PUCPR), Curitiba, Paraná, Brasil

\section{Resumo}

Embora a Psicologia da Religião no Brasil tenha historicamente uma tradição em pesquisa qualitativa, observa-se nos últimos anos um crescimento significativo de publicações de natureza quantitativa. Assim, este texto tem como objetivo apresentar uma análise dos estudos quantitativos em Psicologia da Religião no Brasil, publicados em língua portuguesa. Para isso, procedeu-se um levantamento dos estudos indexados no Banco de Teses e Dissertações da Capes (Coordenadoria de Aperfeiçoamento de Pessoal de Nível Superior) e no Portal de Periódicos SciELO (Scientific Eletronic Library Online) usando vários descritores tais como: “psicologia e religião”, "psicologia

* MRGE: Doutora em Teologia, e-mail: mresperandio@gmail.com

HA: Mestre em Teologia, e-mail: har@@ausland.com.br 
e pesquisa quantitativa”, "religião e validação", "religião e escala”, "religiosidade e escala", "espiritualidade e escala", "escala de bem-estar religioso espiritual”, "escala de coping religioso espiritual”, "psiquiatria e religião", "psiquiatria e pesquisa quantitativa”, "psicologia e validação”, “psiquiatria e validação”. Foram selecionados 70 trabalhos para análise. Os resultados evidenciam que estudos em “psicologia e religião" vem de diferentes áreas de conhecimento levantando a questão sobre a especificidade do campo "psicologia da religião". As pesquisas quantitativas apontam uma tendência de crescimento, principalmente na utilização de escalas. Os estudos indicam a necessidade de aprofundamento na reflexão sobre o papel da religiosidade e espiritualidade na saúde, nos processos de construção de sentido e propósito na vida, nos sentimentos de bem-estar espiritual e na promoção da saúde mental. Considerando que tais temas vêm sendo abordados desde campos diversos, sugere-se, para fins de fortalecimento da Psicologia da Religião como área de conhecimento, a condução de estudos de natureza quali-quanti com base teórica e empírica próprias dessa disciplina.

Palavras-chave: Psicologia da Religião. Estudos quantitativos. Pesquisa. Escalas.Espiritualidade /religiosidade.

\section{Abstract}

Although in Brazil Psychology of Religion historically has a tradition in qualitative research, in recent years it has been possible to observe a significant growth of quantitative publications. Thus, this paper aims to present an analysis of quantitative studies in Psychology of Religion in Brazil, published in Portuguese. For this, we surveyed indexed studies in the CAPES Bank of Theses and Dissertations (Coordination of Higher Education Personnel Training) and SciELO Journal Portal (Scientific Electronic Library Online), using several search terms such as "psychology and religion", "psychology and quantitative research", "religion and validation", "religion and scale", "religiosity and scale", "spirituality and scale", "spiritual/religious well-being scale", "spiritual/religious coping scale", "psychiatry and religion", "psychiatry and quantitative research", "psychology and validation" and "psychiatry and validation". We selected 70 studies for analysis. The results show that studies on "Psychology and religion" come from different areas of knowledge, raising the question of the specificity of "Psychology of Religion". The quantitative research indicates a trend of growth, especially in the use of scales. Studies indicate the need for further 
reflection on the role of religiosity and spirituality on health, on meaning construction and meaning in life processes, on feelings of spiritual well-being and promotion of mental health. Considering that these issues have been addressed from diverse fields, in order to strengthen Psychology of Religions a field of knowledge, we suggested the conduction of studies of qualitative and quantitative nature in the theoretical and empirical perspective of this discipline itself.

Keywords: Psychology of Religion. Quantitative studies. Research. Scales. Spirituality/ religiosity.

\section{Introdução}

Até 2010, os estudos em psicologia da religião no Brasil eram predominantemente de natureza qualitativa, sendo a maioria deles em abordagem fenomenológica, conforme observam Esperandio \& Marques (2014, p. 262). Ao analisarem os estudos publicados no período entre 1956 e 2005, Paiva et al. (2009) observam que 60\% dos estudos demonstravam a preferência pela abordagem conceitual, "à luz da perspectiva psicodinâmica” (PAIVA et al., 2009, p. 445), e que apenas $22 \%$ deles eram de natureza empírica, mas ainda de caráter predominantemente qualitativo (PAIVA et al., 2009, p. 445). Nos últimos anos, o número de estudos quantitativos tem aumentado, conforme veremos a seguir. Este estudo tem por objetivo apresentar os mais recentes dados acerca da pesquisa quantitativa em psicologia da religião no Brasil.

Como ponto de partida, é importante ressaltar que a Psicologia da Religião (PR) não tem como preocupação o exame da natureza ou da existência de Deus. Ela também não é o estudo dos conteúdos psicológicos presentes nas diversas religiões, já que nesse caso seria uma "psicologia religiosa”, como por exemplo, a Psicologia Budista, a Psicologia Cristã.

O foco da Psicologia da Religião está em como as percepções do que o sujeito considera como sagrado impactam a tessitura, o teor, a direção e a qualidade da vida interior de indivíduos e de grupos. Tais experiências e percepções do sagrado constituem-se como componentes fundamentais 
no que diz respeito ao modo como as pessoas organizam e dão sentido ao seu território existencial e constroem seu senso de identidade. As vivências religiosas/espirituais pelas quais as pessoas passam ao longo da vida afetam o funcionamento humano, sobretudo em sua expressão psicológica, ou seja, no sistema de construção de sentido. Bom lembrar que o sistema de construção de sentido de um sujeito não é algo meramente intrapsíquico nem mesmo desvinculado de um contexto mais amplo. A construção de sentido que se dá na dimensão individual dependente, também, da configuração do social, da cultura onde o sujeito se encontra historicamente "subjetivado" (produzido). Para Belzen, "a Psicologia da Religião não é inteiramente diferente de outras disciplinas desenvolvidas nos primeiros tempos da Psicologia; tampouco é uma subdisciplina separada ou simplesmente um campo de aplicação. Dito de modo abrangente, a Psicologia da Religião é uma abordagem situada no campo da Psicologia que tenta descrever, investigar e interpretar o inter-relacionamento entre a cultura e o funcionamento psíquico" (BELZEN, 2009, p. 9). Belzen aponta, nessa definição, a religião como parte da cultura e prioriza uma psicologia cultural da religião. Tentativas de definir o que é psicologia da religião levam inevitavelmente à percepção da complexidade de tal tarefa, e o rico debate que daí advém aponta para o fato de que nenhuma teoria psicológica dá conta sozinha, de compreender a relação entre religião e o funcionamento psíquico. Não há, portanto, "uma" psicologia da religião, mas distintas abordagens que se complementam. Apenas para citar algumas, temos a Psicologia Cultural da Religião, a Psicologia Social da Religião, a Psicologia Cognitiva da Religião, a Psicologia Evolutiva da Religião, entre várias outras. Cada uma delas oferece uma perspectiva parcial na compreensão psicológica do fenômeno religioso e do comportamento religioso. Do mesmo modo, os instrumentos utilizados na realização das investigações em PR são diversos e cada um deles traz contribuições específicas que enriquecem tal campo de conhecimento.

Em uma análise sobre a Psicologia da Religião no Brasil, com base na produção de periódicos e livros, no período entre 1956 a 2005, Paiva, Zangari e colaboradores (2009, p. 442) observaram que os estudos qualitativos nesse campo eram até então, predominantes, embora uma 
tendência a estudos quantitativos estivesse começando a aparecer no final da década de 90 e começos do novo século.

No Brasil, estudos sobre o comportamento religioso em abordagem psicológica podem ser encontrados principalmente em Programas de Psicologia, Ciências da Religião e Teologia (ESPERANDIO \& MARQUES, 2014, p. 259). Contudo, tais estudos se desenvolvem também em Programas de outras áreas do conhecimento, tais como a área da Saúde, por exemplo. O que se observa no Brasil em relação à PR é que este campo é bastante difuso, e os pesquisadores vêm de áreas diversas, compreendendo não apenas psicólogos, mas também médicos psiquiatras, enfermeiros e outros profissionais da área da saúde.

Um levantamento realizado em 2013 por Esperandio \& Marques (2014), sobre pesquisas em PR nos Programas de Pós-graduação no Brasil, apontou que dos 72 programas em Psicologia ${ }^{1}$, seis deles desenvolvem pesquisas em PR. Dos 19 Programas de Teologia/Ciências da Religião, oito deles (três em Teologia ${ }^{2}$ e cinco em Ciências da Religião ${ }^{3}$ ) desenvolvem estudos em PR. Também no campo da Medicina ${ }^{4}$ há vários pesquisadores desenvolvendo trabalhos nessa interface, em três diferentes Programas.

Dadas essas características da psicologia da religião no Brasil, um levantamento das pesquisas quantitativas torna-se uma tarefa problemática: onde buscar e como identificar tais pesquisas quantitativas nesse campo?

1 Os Programas encontram-se nas seguintes instituições: 1. Universidade de São Paulo (USP-SP); 2. Universidade de São Paulo (USP-Ribeirão); 3. Universidade Federal do Paraná (UFPR); 4. Universidade Católica de Brasília (UCB); 5. Universidade Federal de Minas Gerais (UFMG); Pontifícia Universidade Católica de São Paulo (PUC-SP).

2 Programas de Mestrado/Doutorado em Teologia: 1. Pontifícia Universidade Católica do Paraná (PUCPR); 2. Pontifícia Universidade Católica do Rio de Janeiro (PUC-Rio); 3. Escola Superior de Teologia/Instituto Ecumênico de Pós-Graduação (EST/IEPG).

3 Os Programas encontram-se nas seguintes instituições: 1. Universidade Federal da Paraíba (UFPB); 2. Universidade Católica de Pernambuco (UNICAP); 3. Universidade Federal de Juiz de Fora (UFJF); 4. Pontifícia Universidade Católica de São Paulo (PUC-SP); 5. Universidade Mackenzie)

4 Universidade Federal de Juiz de Fora, no Programa de Pós-Graduação em Saúde Brasileira; no Instituto de Psiquiatria da Universidade de São Paulo, e na Universidade Federal do Rio Grande do Sul - UFRGS, na Faculdade de Medicina, no Programa de Mestrado Profissional Ensino na Saúde. 


\section{Metodologia}

Diante do acima exposto, a estratégia utilizada para o levantamento dos dados foi a escolha de alguns termos de busca que pudessem capturar estudos que pudéssemos caracterizar como quantitativos em psicologia da religião, independentemente da área de conhecimento. Os termos de busca foram: "psicologia e religião", "psicologia e pesquisa quantitativa", "religião e validação", "religião e escala", "religiosidade e escala", "espiritualidade e escala", "escala de bem-estar religioso espiritual", "escala de coping religioso espiritual", "psiquiatria e religião", "psiquiatria e pesquisa quantitativa", "psicologia e validação", "psiquiatria e validação", e "sentido da vida e escala". Utilizamos duas bases de consulta: o Banco de Teses e Dissertações da Capes (Coordenadoria de Aperfeiçoamento de Pessoal de Nível Superior) e o Portal de Periódicos SciELO (Scientific Eletronic Library Online).

O Banco de Teses e Dissertações da Capes ${ }^{5}$ é uma base de dados que armazena todos os trabalhos dos programas de pós-graduação no Brasil. Já o Portal de Periódicos SciELO é uma biblioteca eletrônica que abrange uma coleção selecionada contemplando 344 periódicos científicos brasileiros indexados em sua base de dados, constituindo-se assim numa excelente fonte de consulta. Ambas as bases de dados têm vantagens e limitações. O Banco de Teses e Dissertações da CAPES está em processo de reestruturação do sistema, e quanto ao SciELO, há periódicos brasileiros de muito boa qualidade (Estratos Superiores no Qualis: A1, A2 e B1), que não estão indexados nessa plataforma de busca.

Para a coleta de dados no Banco de Teses e Dissertações da Capes, foi realizada uma busca verificando quais publicações continham nossos termos de busca nos resumos. A partir da lista de publicações identificadas nessa pesquisa, cada trabalho foi analisado individualmente para avaliar se o mesmo utilizou a pesquisa quantitativa como método e se o referido trabalho estava relacionado à psicologia da religião. Foram

5 A Base de dados da CAPES vem passando por uma reestruturação do sistema já por um significativo período de tempo. Embora conscientes de que essa fonte de pesquisa encontra-se bastante incompleta e com alguns problemas, ainda assim optamos por mantê-la como fonte de busca, em razão de ser esse o principal banco de dados das pesquisas realizadas no contexto acadêmico dos Programas de Pós-graduação no Brasil. Porém, uma nova busca deve ser realizada no futuro, após a finalização da reestruturação do sistema. 
Tabela 1 - Seleção de Teses e Dissertações da CAPES

\begin{tabular}{|c|c|c|}
\hline Termos de busca utilizados & $\begin{array}{l}\text { Teses e Dissertações } \\
\text { Localizadas }\end{array}$ & $\begin{array}{l}\text { Teses e Dissertações } \\
\text { Selecionadas }\end{array}$ \\
\hline Psicologia e religião & 34 & 3 \\
\hline $\begin{array}{l}\text { Psicologia e pesquisa } \\
\text { quantitativa }\end{array}$ & 01 & - \\
\hline Psiquiatria e religião & 02 & - \\
\hline $\begin{array}{l}\text { Psiquiatria e pesquisa } \\
\text { quantitativa }\end{array}$ & - & - \\
\hline Psicologia e validação & 15 & - \\
\hline Psiquiatria e validação & 3 & - \\
\hline Religião e validação & 5 & 02 \\
\hline Religião e escala & 40 & 14 \\
\hline Religiosidade e escala & 32 & 14 \\
\hline Espiritualidade e escala & - & - \\
\hline $\begin{array}{l}\text { Escala de bem-estar } \\
\text { religioso espiritual }\end{array}$ & - & - \\
\hline Escala de coping religioso & 5 & 5 \\
\hline Sentido de vida e escala & 2 & 2 \\
\hline Soma & 139 & 40 \\
\hline Publicações Duplicadas & & -15 \\
\hline Total & & 25 \\
\hline
\end{tabular}

Fonte: Elaborado pelos autores.

selecionados 25 estudos quantitativos, identificados como próprios do campo da psicologia da religião (Ver tabela 1).

Procedimento análogo foi feito para coletar os dados no Portal de Periódicos SciELO (Ver tabela 2). Após uma primeira busca com os mesmos termos usados no Banco da CAPES, todos os trabalhos foram analisados individualmente, descartadas as duplicações e selecionados os estudos quantitativos ligados à psicologia da religião. Encontramos, assim, 45 estudos quantitativos que, somados às 25 teses e dissertações totalizaram 70 trabalhos.

A partir da seleção dessas 70 publicações foi procedida a catalogação dos seguintes dados desses documentos numa planilha de cálculo Excel ${ }^{\circledR}$ : título, autor(es), ano da publicação, tema, tipo de pesquisa (criação de escala, 
validação de escala, aplicação de escala, aplicação de questionário próprio), qual/quais escala(s) utilizada(s), base de dados consultada e natureza da publicação (tese de doutoramento, dissertação de mestrado, artigo científico). Adicionalmente, para as teses e dissertações, foi anotada a instituição de ensino e o curso pelo qual o trabalho foi produzido. Para os artigos, foi registrado o nome da revista na qual os mesmos foram publicados.

Após a tabulação dos dados, a planilha de cálculo foi carregada num software de inteligência de dados, denominado Qlik Sense, com o qual foram feitos os gráficos comparativos utilizados neste artigo.

Tabela 2 - Seleção de Artigos Científicos no SciELO

\begin{tabular}{|c|c|c|}
\hline Termos de busca utilizados & Artigos Localizados & Artigos Selecionados \\
\hline Psicologia e religião & 21 & 3 \\
\hline $\begin{array}{l}\text { Psicologia e pesquisa } \\
\text { quantitativa }\end{array}$ & 10 & - \\
\hline Psiquiatria e religião & 7 & - \\
\hline $\begin{array}{l}\text { Psiquiatria e pesquisa } \\
\text { quantitativa }\end{array}$ & 2 & - \\
\hline Psicologia e validação & 17 & - \\
\hline Psiquiatria e validação & 8 & - \\
\hline Religião e validação & 2 & 2 \\
\hline Religião e escala & 28 & 11 \\
\hline Religiosidade e escala & 21 & 16 \\
\hline Espiritualidade e escala & 23 & 19 \\
\hline $\begin{array}{l}\text { Escala de bem-estar } \\
\text { religioso espiritual }\end{array}$ & 2 & 2 \\
\hline Escala de coping religioso & 10 & 8 \\
\hline Sentido de vida e escala & 16 & 6 \\
\hline Soma & 167 & 67 \\
\hline Publicações Duplicadas & & -22 \\
\hline Total & & 45 \\
\hline
\end{tabular}

Fonte: Elaborado pelos autores. 


\section{Resultados}

\section{Produções por Ano}

Paiva e colaboradores (2009) observaram um número pequeno de estudos empíricos, 22\%. Contudo, mesmo "os estudos empíricos e aplicados têm sido predominantemente de caráter qualitativo" (PAIVA et al., 2009, p. 442). Assim, o levantamento ora realizado aponta uma novidade na tendência atual. Os dados indicam que as pesquisas quantitativas em psicologia da religião vêm apresentando um incremento gradual ao longo do tempo. Ainda que possa haver problemas de precisão no Banco de Dados da Capes, é notável que a partir de 2011 cresce significativamente o número de artigos, teses e dissertações de caráter quantitativo, perfazendo um total de 57 estudos, contra um total de 13 estudos realizados entre o período de 2003 a 2010. Em relação ao número de artigos publicados, observa-se volume semelhante, no mesmo período de tempo: de 2003 a 2010, 13 artigos e de 2011 a meados de 2015, 32 artigos. Tais evidências, ao mesmo tempo em que apontam uma tendência significativa no aumento de estudos quantitativos a partir de 2011, sobre "psicologia e religião", levantam a questão se de fato, eles se configurariam como estudos propriamente "de psicologia da religião".

\section{Produções por Região e Área de Conhecimento}

As teses e dissertações catalogadas neste artigo foram produzidas em 13 instituições de ensino, representando quase todas as regiões do país. O Nordeste está representado pela UFPB, UFCE e UFRN. O CentroOeste está representado pela UnB e UFGO. A Região Sudeste está representada pela USP, PUCSP, Universidade Presbiteriana Mackenzie, UFMG e Fundação Antônio Prudente. Finalizando, a Região Sul está representada pela PUCPR, PUCRS e UNISINOS.

A amplitude da penetração dos temas da psicologia da religião também se evidencia pela variedade de cursos de mestrado e doutorado pelos 
quais as dissertações e teses foram defendidas. Os cursos foram agrupados da seguinte maneira (Gráfico 3):

a) Ciências da Saúde: Foram encontrados doze estudos, distribuídos nas seguintes áreas: Ciências da Saúde, Ciências Médicas, Processos de Desenvolvimento Humano e Saúde, Enfermagem, Enfermagem Fundamental, Enfermagem na Saúde do Adulto, Neurociências, Oncologia, Gerontologia Biomédica;

b) Psicologia: Foram encontrados seis estudos em Psicologia e Psicologia Social;

c) Teologia/Ciência das Religiões: Nesta área foram publicados sete estudos.

Os temas da psicologia da religião perpassam diferentes áreas do conhecimento, com predominância na área das ciências da saúde. O volume de estudos nas áreas da psicologia e da teologia/ciência das religiões é semelhante.

Artigos que tratam de pesquisa quantitativa em psicologia da religião foram publicados em 24 revistas de diferentes áreas (Gráfico 4). As publicações foram agrupadas de acordo com as áreas a seguir descritas:

a) Ciências da Saúde: Trinta estudos foram publicados nos seguintes periódicos: Ciênc. saúde coletiva, Rev. Saúde Pública, Cad. Saúde Pública, Acta paul. enferm., J. bras. psiquiatr., Rev. esc. enferm. USP, Rev. Latino-Am. Enfermagem, Arch. Clin. Psychiatry (São Paulo), Texto contexto - enferm., Saúde debate, Rev. psiquiatr. Rio Gd. Sul, Rev. bras. geriatr. gerontol., Arq. Bras. Cardiol., São Paulo, Med. J., Rev. Bras. Psiquiatr.;

b) Psicologia: Quatorze estudos foram publicados nas seguintes revistas: Psicol. estud., Psic.: Teor. e Pesq., Psicol. Reflex. Crit., Psicol. Soc., Paidéia (Ribeirão Preto), Estud. psicol. (Campinas), Psicol. cienc. prof., Psicol. USP;

c) Educação: Um único estudo publicado na Revista Educ. Pesqui. 
Considerando que os estudos quantitativos se encontram predominantemente na área da Saúde, dois terços dos artigos foram publicados nas revistas dessa área, seguidos por publicações em áreas da psicologia.

\section{Utilização de Escalas}

Os estudos foram classificados de acordo com o tipo de pesquisa realizada. A maioria (85\%) dos trabalhos aplica escalas já validadas. No período entre 2003 a 2015, foram encontrados:

- 59 estudos quantitativos com aplicação de escalas já validadas;

- 6 estudos com validação de novas escalas: Escala de Coping ReligiosoEspiritual (PANZINI \& BANDEIRA, 2005), Escala WHOQOL Módulo espiritualidade, religião e crenças pessoais (PANZINI et al., 2011); Daily Spiritual Experience Scale (KIMURA et al., 2011); Escala de Religiosidade de Duke - DUREL (TAUNAY et al., 2012); The Resilience Scale (CARVALHO et al., 2012); Questionário de Sentido da Vida (AQUINO et al., 2015);

- 3 estudos utilizaram questionários próprios;

- 2 estudos apresentaram a criação/validação de duas novas escalas: Índice De Religiosidade Intrínseca (Taunay et al., 2012b); Índice de Compromisso Religioso - ICR (SANTOS et al., 2012).

Dentre as escalas mais frequentemente utilizadas estão: a Escala de Coping Religioso-Espiritual (PANZINI \& BANDEIRA, 2005), a Escala WHOQOL (PANZINI et al., 2011) a Escala de Religiosidade DUREL (TAUNAY et al., 2012) e a Escala de Bem-Estar Espiritual (MARQUES et al., 2009), respondendo, juntas, por mais da metade dos trabalhos. Observa-se que em 2011 e 2012 houve um aumento significativo na utilização dessas escalas (Gráfico 1). 


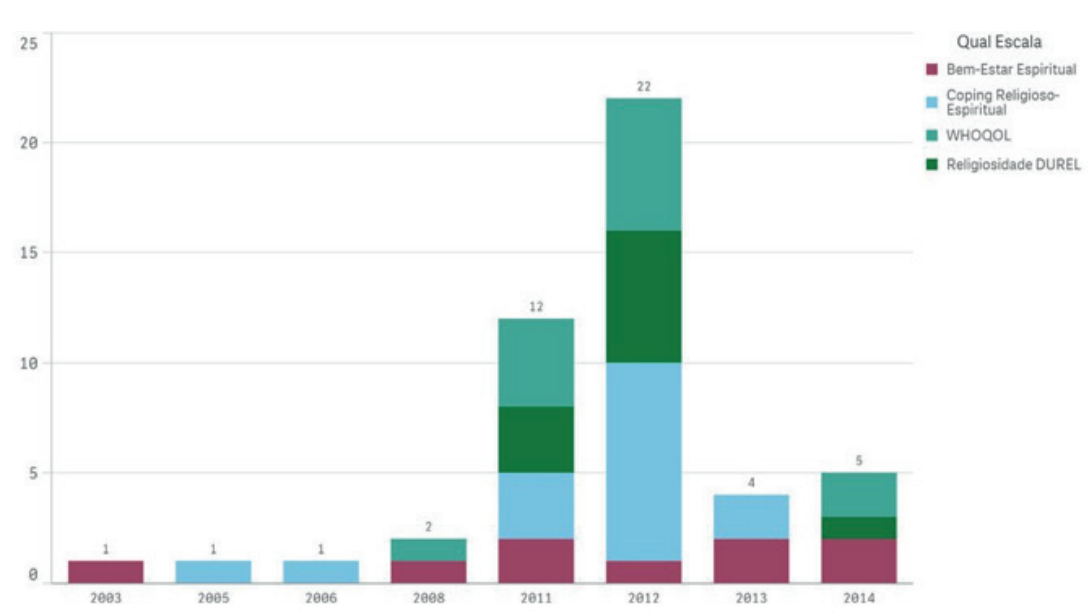

Gráfico 1 - Aplicação das Principais Escalas, por Ano Fonte: Elaborado pelos autores.

\section{Categorização dos temas das pesquisas}

Na classificação das publicações em categorias temáticas, foram encontrados estudos sobre espiritualidade e saúde, coping religioso-espiritual, valores, virtudes e crenças, qualidade de vida e religiosidade/espiritualidade, e sentido de vida, nas proporções tais como apontadas no Gráfico 2.

\section{Espiritualidade e Saúde}

O tema da espiritualidade e saúde predomina nas pesquisas quantitativas, perfazendo $41,4 \%$ das publicações analisadas. Os estudos selecionados para essa categoria compreendem a criação da escala "Índice de Religiosidade Intrínseca” e 28 aplicações da mesma na avaliação da religião e espiritualidade de idosos, de adolescentes, de pós-graduandos, de pacientes com insuficiência renal, de estudantes de psicologia, de adventistas do sétimo dia, de psicólogos, de pacientes com epilepsia, de profissionais de saúde, de pessoas frequentadoras do Santo Daime e Umbanda, de pacientes com câncer, com HIV/AIDS, entre outros. 


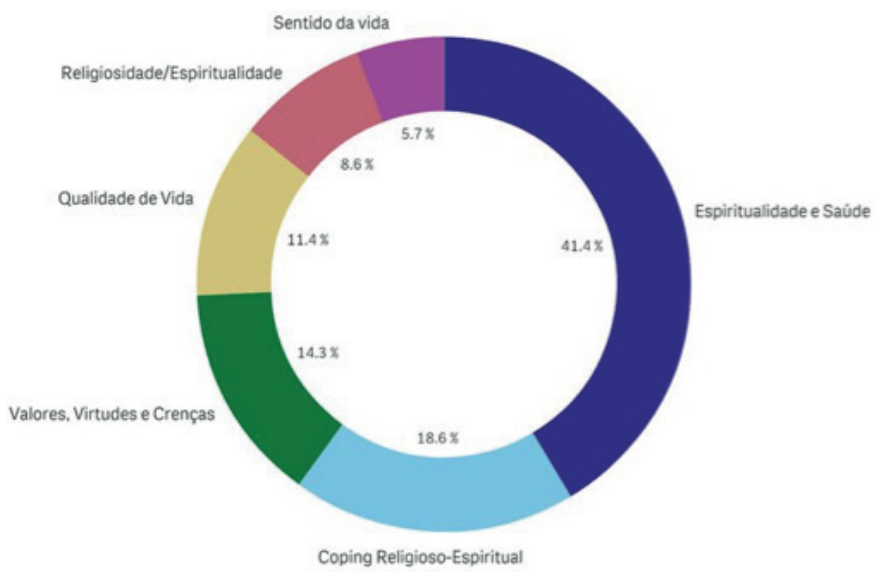

Gráfico 2 - Temas das Publicações

Fonte: Elaborado pelos autores.

\section{Coping Religioso-Espiritual}

Pesquisas sobre coping religioso-espiritual representam o segundo maior volume de trabalhos, com 18,6 \% do total. Essas publicações tratam desde a validação da Escala de Coping Religioso - Espiritual - Escala CRE (PANZINI \& BANDEIRA, 2005), e de outros onze estudos empíricos com aplicação desse instrumento. As pesquisas investigam o coping religioso-espiritual de idosos, de pacientes com câncer, de pessoas com HIV/AIDS, de familiares de pacientes de UTI, de pacientes com Hepatite $C$, de mulheres presbiterianas com estresse, de pastores pentecostais, de pessoas com doença renal, entre outros.

\section{Valores, Virtudes e Crenças}

Os estudos sobre esse tema foram desenvolvidos com a utilização da escala The Resilience Scale, com aplicação da mesma em seis trabalhos, e outros três estudos com a utilização de questionários próprios. 
Tais investigações tratam dos valores priorizados por estudantes de psicologia, do tabagismo em acadêmicos da área de saúde, da atitude frente à dor em trabalhadores, da preocupação com a honra no Nordeste, de adolescentes com transtorno de conduta, de adolescentes com depressão, do uso de álcool e espiritualidade entre estudantes de enfermagem e da sexualidade de jovens evangélicos e do amor entre jovens.

\section{Qualidade de Vida}

As publicações sobre qualidade de vida tratam da validação de uma escala (Escala WHOQOL) e de 7 aplicações das mesmas em investigações que visam correlacionar religião, religiosidade/espiritualidade e qualidade de vida de jovens, adultos, idosos, universitários de psicologia e pacientes após a revascularização do miocárdio.

\section{Religiosidade/Espiritualidade}

Os estudos quantitativos com enfoque específico na religiosidade/ espiritualidade valeram-se do Índice de Compromisso Religioso - ICR, tanto de sua criação como validação, bem como a validação de duas outras escalas, a de Religiosidade DUREL e da Daily Spiritual Experience Scale. Foram encontrados três estudos que se utilizaram dessas escalas para avaliar a espiritualidade de acadêmicos de psicologia, de universitários e de pacientes psiquiátricos.

\section{Sentido da Vida}

Os estudos quantitativos sobre esse tema dizem respeito à validação do Questionário sobre o Sentido da Vida, e de 3 aplicações de escalas avaliar o sentido da vida de idosos e de mulheres com cancro da mama e de pessoas com HIV/AIDS. Destacam-se no estudo sobre sentido da vida 
e religiosidade, os estudos empíricos de Thiago Aquino, com base no referencial teórico de Viktor Frankl.

\section{Discussão}

Os estudos evidenciam que a pesquisa quantitativa em psicologia da religião, no Brasil não se restringe ao campo da Psicologia ou a uma única área de pesquisa. Contudo, como bem observam Paloutzian \& Park (2013) em recente reedição do Manual de Psicologia da Religião e Espiritualidade, "o campo da psicologia da religião e espiritualidade está se tornando mais difuso e as pesquisas estão crescendo não somente entre psicólogos que se identificam como especialistas neste domínio específico, mas por muitos psicólogos, sociólogos, pesquisadores da área do cuidado em saúde, antropólogos, neurocientistas cognitivos, e outros" (PALOUTZIAN \& PARK, 2013, p. 661). Para os autores, tal penetração da PR, incluindo sua utilização por outras disciplinas não significa que o caráter distinto da PR irá desaparecer. Para eles, "psicólogos e pesquisadores de outras disciplinas há tempos tem estudado religiosidade e a espiritualidade, e, enquanto esta atenção multidisciplinar continuar, é provável que continue tais trabalhos quando focalizam os aspectos psicológicos, certamente contribuirão com o corpus de pesquisa em psicologia da religião e espiritualidade, independentemente do título ou do treinamento dos pesquisadores que estão conduzindo tais estudos" (PALOUTZIAN \& PARK, 2013, p. 661). As observações dos autores referem-se, sobretudo, à realidade estadunidense. Contudo, percebemos a mesma tendência no contexto brasileiro.

Os dados mostram, ainda, que o interesse em pesquisa quantitativa tem crescido sobretudo nas Ciências da Saúde, em especial nas pesquisas enfocando a relação entre espiritualidade e saúde. Tal interesse pode se relacionar ao fato de que a importância da integração da dimensão da espiritualidade nos contextos das práticas dos cuidados em saúde vem sendo confirmada com pesquisas que se preocupam em apresentar dados estatísticos. Assim, vem se ampliando também os estudos que se utilizam de escalas para levantamento de dados, fazendo crescer também a variedade 
de escalas que estão sendo disponibilizadas em português, para as pesquisas em psicologia da religião e espiritualidade, como as recentes validações de Aquino (2015), com o "Questionário de Sentido da Vida" e a "Escala de Atitudes Religiosas, Versão Expandida (EAR-20)" uma versão atualizada e revisada das escalas anteriores criadas pelo mesmo autor (AQUINO et al., 2013). Como aponta Marques e Aguiar (2013) em um estudo sobre instrumentos de mensuração da religiosidade/espiritualidade, existem atualmente, cerca de 19 instrumentos disponíveis em língua portuguesa.

A maioria das escalas utilizadas tem sido traduzidas, adaptadas e validadas para o contexto brasileiro, destacando-se: a Escala de Coping Religioso Espiritual, a Escala de Bem-Estar Espiritual, a Escala de Qualidade de Vida - WHOQOL, e a Escala de Religiosidade DUREL. Aos poucos começam a surgir escalas criadas especialmente para aplicação na população brasileira, como o Índice de Religiosidade Intrínseca (TAUNAY et al., 2012b); e o Índice de Compromisso Religioso - ICR (SANTOS et al., 2012).

\section{Considerações Finais}

Os dados levantados para este estudo apontam a relevância das investigações em psicologia da religião, independentemente da área onde tais estudos são conduzidos. No contexto brasileiro no qual a religiosidade tem papel central na subjetividade de grande parte da população, os estudos quantitativos atestam com dados estatísticos contundentes, a premência e relevância da reflexão nesse campo de conhecimento. Os estudos sugerem a necessidade de aprofundamento na reflexão sobre o papel da religiosidade e espiritualidade na saúde, nos processos de construção de sentido e propósito na vida, nos sentimentos de bem-estar espiritual e na promoção da saúde mental. Se por um lado, os estudos empíricos baseados em evidências, causam impacto em função dos dados estatísticos robustos, por outro lado, deixam escapar dados importantes que são levantados nos estudos de natureza qualitativa.

Os estudos quantitativos apontam uma tendência de crescimento, sobretudo, com utilização de escalas para levantamento de dados. Nesse sentido, sugere-se que para o fortalecimento do campo da psicologia da 
religião no Brasil sejam conduzidos estudos quali-quanti, com bases teórica e empírica próprias dessa disciplina, e que se busque também a construção de escalas próprias, ao lado do trabalho de adaptação e a validação das escalas importadas de outras realidades para o contexto brasileiro.

A limitação da revisão ora apresentada diz respeito às bases de dados disponíveis, neste momento para este tipo de levantamento. Há trabalhos interessantes em psicologia da religião publicados em revistas não indexadas no SciELO. Contudo, a seleção de trabalhos em revistas não indexadas seria problemática, dada a dificuldade tanto no estabelecimento de critérios para tal seleção (correndo o risco de uma seleção enviesada e parcial), quanto de procedimentos técnicos para a realização da busca. Somado a este aspecto, também o fato da maior base de dados do Brasil (Banco de Teses e Dissertações da CAPES) estar passando por uma reestruturação já há algum tempo. Esta base reúne todos os trabalhos acadêmicos produzidos nos programas de pós-graduação no país. Entretanto, apesar das limitações apontadas, os dados nos permitem ver as tendências atuais da pesquisa em psicologia da religião no Brasil, em termos de metodologia, temas investigados, áreas de onde vem tais pesquisas, como também não deixa dúvidas sobre o crescente interesse acadêmico nesse campo de conhecimento.

O maior número de estudos quantitativos se concentra sobre espiritualidade e saúde. Entretanto, se comparada à literatura internacional, a pesquisa sobre este tema está apenas começando, mas desponta como um dos principais tópicos com maior potencial para fomentar os estudos em Psicologia da Religião no Brasil.

\section{Referências}

AQUinO, T. A. A. de; VEloso, V. G.; AGUIAR; A. A. de; SERAFIM, T. D. B; PONTES, A. de M; PEREIRA, G. de A., \& FERNANDES, A. S. Questionário de Sentido de Vida: Evidências de sua Validade Fatorial e Consistência Interna. Psicol. cienc. prof., Brasília, v. 35, n. 1, p. 4-19, mar. 2015. 
AQUINO, T. A. A. de; GOUVEIA, V. V.; SILVA, S. de S.; AGUIAR, A. A. Escala de Atitudes Religiosas, Versão Expandida (EAR-20): Evidências de Validade. Avaliação Psicológica, v. 12, 2013. p. 109-119.

AQUINO, T. A. A. et al. Atitude religiosa e sentido da vida: um estudo correlacional. Psicologia: Ciência e Profissão, v. 29, p. 228-243, 2009.

CAPES. Banco de Teses. Brasília, 2014. Disponível em: <http://aviso.capes.gov.br/ bancodeteses/aviso.html>. Acesso em 21/09/2015.

ESPERANDIO, M.R.G.; MARQUES, L.F. The Psychology of Religion in Brazil. The Internatinal Journal for the Psychology of Religion, v. 25, n. 4, p. 255-271, 2014.

MARQUES, L. F.; SARRIERA, J. C.; DELL'AGLIO, D. D. Adaptação e validação da Escala de Bem-estar Espiritual (EBE): Adaptation and validation of Spiritual Well-Being Scale (SWS). Aval. psicol., Porto Alegre, v. 8, n. 2, p. 179-186, ago. 2009.

MARQUES, L. F.; AGUIAR, A. P. A. Instrumentos de mensuração da religiosidade/espiritualidade (R/E) e seus construtos. Instruments for Measuring Religiousness/Spirituality (R/S) and its constructs. Rev. Pistis Prax., Teol. Pastor., Curitiba, v. 6, n. 1, p. 107-126, jan./abr. 2014.

KIMURA, M.; OLIVEIRA, A. L. de; MISHIMA, L. S. \& UNDERWOOD, L. G. Adaptação cultural e validação da Underwood's Daily Spiritual Experience Scale - versão brasileira. Rev. esc. enferm. USP, São Paulo, v. 46, n. spe, p. 99-106, oct. 2012.

PAIVA, G. J. de et al. Psicologia da Religião no Brasil: a produção em periódicos e livros. Psic.: Teor. e Pesq. v. 25, n. 3, p. 441-446, 2009.

PALOUTZIAN, R.; PARK, C. L. Directions for the Future of the Psychology of Religion and Spirituality. In: PALOUTZIAN, R.; PARK, C. L. Handbook of the Psychology of Religion and Spirituality. New York/London: Guilford Press, 2013. p. 650-665.

PANZINI, R. G.; MAGANHA, C.; ROCHA, N. S. da; BANDEIRA; D. R.; FLECK, M. P. Validação brasileira do Instrumento de Qualidade de Vida/espiritualidade, religião e crenças pessoais. Rev. Saúde Pública, São Paulo, v. 45, n. 1, p. 153-165, feb. 2011. 
PANZINI, R. G.; BANDEIRA, D. R. Escala de coping religioso-espiritual (Escala CRE): elaboração e validação de construto. Psicol. estud., Maringá, v. 10, n. 3, p. 507-516, dec. 2005.

SANTOS, W. S. S.; GOUVEIA, V. V.; GUERRA, V. M.; COUTINHO, M. de L.; FERNANDES, D. P. Índice de Compromisso Religioso (ICR): elaboração e evidências psicométricas. Psicologia: Reflexão e Crítica, v. 25, n. 3, p. 523-531, 2012.

SciELO - Scientific Electronic Library Online. São Paulo: FAPESP, 2015. Disponível em: <http://search.SciELO.org/>. Acesso em: 15/09/2015.

TAUNAY, T. C.; Claussen D'Escragnolle; GONDIM, F. A. A. de MACÊDO, D. S; MOREIRA-ALMEIDA, A. GURGEL, L. A. ANDRADE, L. M. S.; CARVALHO, A. F. Validação da versão brasileira da escala de religiosidade de Duke (DUREL). Rev. psiquiatr. clín., São Paulo, v. 39, n. 4, p. 130-135, 2012.

TAUNAY, T. C.; CRISTINO, E. D.; MACHADO, M. O; ROLA, F. H.; LIMA, J. W. O; MACÊDO, D. S.; GONDIM, F. A. A; MOREIRA-ALMEIDA, A.; CARVALHO, A. F. Development and validation of the Intrinsic Religiousness Inventory (IRI). Revista de Psiquiatria Clínica, v. 34, p. 76-81, 2012b.

Recebido: 03/11/16

Received: 03/11/16

Aprovado: 29/02/17

Approved: 29/02/17 
